\title{
Enhancing individual entrepreneurial orientation measurement using a metacognitive decision making-based framework
}

\author{
Fernando A. F. Ferreira ${ }^{1,2}$ - Marjan S. Jalali ${ }^{1}$. \\ Paulo Bento $^{1}$ - Carla S. E. Marques ${ }^{3}$.
}

João J. M. Ferreira ${ }^{4}$

Published online: 22 February 2016

(C) Springer Science+Business Media New York 2016

\begin{abstract}
Entrepreneurship, and individuals' predisposition toward entrepreneurial activities in particular, i.e. Individual Entrepreneurial Orientation (IEO), has been gaining increasing relevance in academia and management practice alike. Understanding IEO is a critical element not only for its promotion, but for better and more informed managerial and investor decision making as well. As such, this study proposes a new framework for understanding and measuring IEO based on the integrated use of cognitive mapping and the interactive multiple criteria decision
\end{abstract}

João J. M. Ferreira

jjmf@ubi.pt

Fernando A. F. Ferreira

fernando.alberto.ferreira@iscte.pt; fernando.ferreira@memphis.edu

Marjan S. Jalali

marjan.jalali@iscte.pt

Paulo Bento

paulo.bento@iscte.pt

Carla S. E. Marques

smarques@utad.pt

1 ISCTE Business School, BRU-IUL, University Institute of Lisbon, Avenida das Forças Armadas, 1649-026 Lisbon, Portugal

2 Fogelman College of Business and Economics, University of Memphis, Memphis, TN 38152-3120, USA

3 Department of Economics, Sociology and Management \& CETRAD Research Unit, University of Trás-os-Montes e Alto Douro, Quinta de Prados, 5000-8001 Vila Real, Portugal

4 Department of Business and Economics \& NECE Research Unit, University of Beira Interior, Estrada do Sineiro, 6200-209 Covilhã, Portugal 
making (TODIM) method. We present the steps for building such a framework, as well as a practical application of these steps. The results are promising: the methodology applied allowed a large number of determinants of IEO and their relationships to be mapped; and, subsequently, ranked and weighted for the creation of an IEO measurement tool. The implications of the resulting framework for theory and practice, its limitations and possibilities for further research are also discussed.

Keywords Individual entrepreneurial orientation - Measurement - Cognitive mapping · TODIM $\cdot$ Multiple criteria decision analysis

JEL Classification $\mathrm{C} 44 \cdot \mathrm{L} 26 \cdot \mathrm{M} 10$

\section{Introduction}

Although entrepreneurship has long captured the interest and attention of academics, economists and business practitioners alike, it has arguably never been as topical or important an issue as it is now. World economies are still reeling in the aftermath of the global financial crisis, and the business context is of increasing global interdependencies, fast paced innovations and intensified competition. Against this backdrop, there has been growing interest in understanding (and promoting) entrepreneurship and the propensity for entrepreneurial activity by firms and individuals (cf. Marques et al. 2013). The underlying assumption is that "entrepreneurship carried on in the pursuit of business opportunities spurs business expansion, technological progress, and wealth creation", and as such serves as a "major engine of economic growth" (Lumpkin and Dess 1996, p. 135).

Entrepreneurial Orientation (EO) can refer to both firms and individuals, and can be a relevant characteristic in the context of both existing firms and new ventures. While definitions of entrepreneurship and EO abound, the former is often understood to encompass "the processes, practices, and decision-making activities that lead to new entry", with new entry being "the essential act of entrepreneurship" (Lumpkin and Dess 1996, p. 136). Typically, EO has been characterized along the dimensions of: i) autonomy (independent action for the advancement and completion of a business concept); ii) innovativeness (for the development of new products/services, technologies or processes); (iii) risk taking; iv) pro-activeness (a forward looking stance for the anticipation and exploration of new opportunities); and v) competitive aggressiveness (in efforts to surpass the competition) (cf. Miller 1983; Lumpkin and Dess 1996; Covin and Wales 2012).

Despite the concept's wide applicability, the literature has sought to more clearly distinguish the entrepreneurial propensities of firms (EO) and that of individuals, termed Individual Entrepreneurial Orientation (IEO). Bolton and Lane (2012), for instance, developed a measure of IEO which is based on three of the five EO dimensions noted above: innovativeness, risk taking and pro-activeness. Such measures are important, because of the relevance of IEO for new business creation, entrepreneurship education and allocation of investment funding, among others. Yet, they are still greatly lacking (cf. Mitchell et al. 2002; Shook et al. 2003). 
Although attempts have been made to create instruments for the measurement of IEO (such as that of Bolton and Lane 2012), or of the closely related concept of Individual Entrepreneurial Intent ("the intention of individuals to set up new businesses" (Thompson 2009, p. 1042)), a consistent approach to the measurement of this intent is still to emerge (Shook et al. 2003). Similar arguments could be made with respect to IEO, particularly in what refers to capturing the concept's inherent complexity. This is because, in addition to more commonly used determinants of IEO, such as those mentioned above, a more comprehensive understanding of the concept would require the incorporation of the more intangible, intuitive and subjective aspects of entrepreneurial predisposition and decision making.

This paper seeks to address this issue, and redress the balance which has typically been tipped in favor of the study of firm- (rather than individual-) level EO, by proposing a new methodological framework for the measurement of IEO. Specifically, we aim to show how cognitive mapping can be integrated with the TODIM (Portuguese acronym for Interactive Multiple Criteria Decision Making) method, to allow for a more comprehensive and in-depth identification, representation and evaluation of the underlying determinants of IEO.

In addition to their ability to promote discussion and learning, cognitive maps allow large numbers of determinants to be identified, visually represented and the interactions between them to be mapped (Eden 2004; Eden and Ackermann 2004). TODIM, in turn, allows these determinants to be ranked, while considering "the bounded rationality of the decision makers based on Prospect Theory" (Liu et al. 2011, p. 560). As such, the method not only rules out the possibility of inconsistencies in the hierarchization of alternatives carried out through pairwise comparisons, but is also able to integrate risk into its frameworks. This is a particularly relevant point, given the importance attributed to risk taking in almost all conceptualizations of EO. By incorporating "Prospect Theory (Kahneman and Tversky 1979) in its formulation", TODIM "considers aversion and propensity to risk during the decision making process" (Rangel et al. 2011). To the best of our knowledge, this is the first attempt to bring together cognitive mapping with TODIM in this context, and as such, can be an important contribution to improve our conceptualization and evaluation of IEO. At the same time, it also presents a contribution to the field of Operational Research (OR), supporting previous calls for the use of OR techniques for the development of appraisal systems (cf. Smith and Goddard 2002; Santos et al. 2008; Ackermann et al. 2011; Howick and Ackermann 2011; Amado et al. 2012; Ferreira et al. 2012, 2015b).

The next section presents an overview of the relevant literature on IEO. The ensuing section then explains the requirements for the integration of cognitive mapping with the TODIM technique for IEO measurement, illustrated by a step-by-step description of our actual development of such an evaluation framework. The final section discusses the strengths, limitations and implications of this approach for both theory and practice.

\section{Related work}

Following Lyon et al. (2000, p. 1056), an Entrepreneurial Orientation "consists of processes, structures, and/or behaviors that can be described as aggressive, innovative, 
proactive, risk taking, or autonomy seeking" (see also Lumpkin and Dess 1996). It is distinct from entrepreneurship in the sense that it refers to "how new ventures are undertaken", rather than "what is undertaken" (Lumpkin and Dess 2001, p. 432; emphasis in the original). In addition, EO can exist both within the firm and within individuals, the latter being the focus of this paper.

Interest in EO has been consistently growing. Rauch et al. (2009, p. 762) point to EO as a "central concept" in entrepreneurship, and "one of the areas of entrepreneurship research where a cumulative body of knowledge is developing". The reasons for this interest relate to the proposed relationship between EO and firm performance. Indeed, "several studies have found that firms demonstrating more entrepreneurial strategic orientation perform better" (Wang 2008, p. 635); a relationship all the more important in the current context of increased competition, faster technological change and high need for economic growth.

While EO has traditionally been analyzed and measured at the firm level, it is equally important to understand individual-level entrepreneurial orientation, insofar as it can have implications not only within firms, but with respect to new enterprise and product development, job creation and macro-level growth. It is of relevance for managers wanting to engage in business partnerships, facing hiring or placement decisions, or dealing with the allocation of resources; as well and for investors wanting to make sound investment decisions. Furthermore, understanding the determinants of IEO can underlie the development of more focused policy decisions for the promotion of entrepreneurship.

The study of IEO, however, is significantly less developed than that of firm level EO, with most studies focusing on the main dimensions of autonomy, innovativeness, risk taking, pro-activeness, and competitive aggressiveness (Lumpkin and Dess 1996). Bolton and Lane (2012), for instance, proposed to develop a measurement instrument for IEO to be used on students and other individuals. The scale development resulted in three distinct factors (i.e. innovativeness, risk-taking and pro-activeness), the same variables used in existing EO literature. The authors argue that "this measurement can be used to assist in entrepreneurship education and in student team who want to assess the strength of their orientation toward entrepreneurship" (Bolton and Lane 2012, p. 219) (for discussion, see Spedale and Watson 2014; Goktan and Gupta 2015). Rauch et al. (2009, p. 762) note that "similar measurement instruments have been applied across a wide array of studies", a reality which has led several authors to argue for more comprehensive measures of IEO, using alternative methods (cf. Lyon et al. 2000; Li et al. 2009).

Miller (1983), who proposed one of the best known measures of EO, which served as the basis for the now more commonly used conceptualization proposed by Lumpkin and Dess (1996), in reviewing his seminal paper almost 30 years later noted the "tendency to adhere to the same measures of EO year after year, based on instruments that were developed decades ago" (Miller 2011, p. 879). At the top of his recommendations for future research in the field was, thus, finding "alternative operationalizations of the EO construct" (idem).

This paper aims to do that by integrating cognitive mapping with the TODIM method - an integrated combination that, to the best of our knowledge, has not yet been applied to the field of IEO. Although this combination of methodologies is new, it should be underlined that this study is based on previous work by Ferreira et al. 
(2015c). In that study, the integrated use of cognitive mapping with the measuring attractiveness by a categorical evaluation technique (MACBETH) was proposed for IEO measurement and management. The current study builds on that work by using the TODIM method. In this sense, it is markedly different, because it integrates risk into the decision framework. As already pointed out, this is a particularly relevant point, given the importance attributed to risk taking in conceptualizations of IEO. The next sections describe the application of the combined use of cognitive maps and TODIM, as well as the resulting framework and its practical application.

\section{A new measurement system}

The idea of integrating cognitive maps with Multiple Criteria Decision Analysis (MCDA) techniques is not new. It has been successfully applied in different contexts, with promising results in terms of the potential applications and implications of such integrated methodologies (e.g. Ferreira et al. 2011; Ferreira et al. 2012; Filipe et al. 2015; Ferreira et al. 2015c). The combination of cognitive mapping with the TODIM technique in the area of EO, and IEO in particular, however, is to the best of our knowledge novel; and expected to yield many of the same benefits in terms of transparency, comprehensiveness and ability to promote learning.

Indeed, cognitive maps are widely known for their capacity to tap into and build collective knowledge, on the basis of group discussions in a posture of learning. As such, they are typically able to identify a vast number of determinants within any given decision problem, as well as the relationships between them. These are then visually represented, facilitating "communication, [supporting] the identification and the interpretation of information, [facilitating] consultation and codification, and [stimulating] mental associations" (Gavrilova et al. 2013, p. 1756). In addition, transparency is increased by the clear identification of the origin of the determinants used in the resulting evaluation framework; which, in this case, will be developed using TODIM. The TODIM approach allows alternatives to be ranked according to decision makers' evaluations, whilst taking attitudes toward risk, as presented in Prospect Theory, into account. Its formulation precludes the possibility of inconsistent assessments, and the incorporation of risk makes it particularly suited to the analysis of IEO.

The combination of cognitive mapping with MCDA techniques allows some of the shortfalls of more commonly used methodologies to be overcome. Ananda and Herath (2009), for instance, note that with traditional methodologies there is always the risk that the actual behavior of respondents may be different than their estimated behavior. Another widely cited criticism to these techniques is that attributes understood as less important relative to others might be omitted by some decision makers - but that these attributes might potentially be decisive when everything else is equal, as is often the case. Another theoretical drawback of the use of traditional approaches is that the number of comparisons required for reliable priority estimations can be daunting when many criteria or alternatives are presented simultaneously (van Til et al. 2008) - the so called number-of-attribute-levels effect (Wittink et al. 1982, 1989; Steenkamp and Wittink 1994). These limitations are largely overcome through the combined use of cognitive maps with MCDA techniques proposed in the current paper, which enables a large number of determinants and their cause-and-effect relationships to be identified, 
and increases transparency, in the sense that it is clear where the data is coming from (cf. Ackermann and Eden 2001). In addition, with TODIM in particular, the relative importance among the criteria is calculated taking risk into account (and according to the experts' own perceptions of that importance), after discussion and negotiation among the panel members; whereby subjectivity is not only made explicit, it is incorporated and turned into a strength of the process.

The next sections describe our application and integration of cognitive mapping and TODIM for the creation of a framework for the evaluation of IEO in three main stages: i) the structuring phase, during which a collective cognitive map was developed; ii) the evaluation phase, which allowed the criteria identified in the first step to be weighted and hierarchically arranged; and iii) the recommendations phase, in which the resulting framework as a whole was assessed.

\section{The structuring phase - participants and problem definition}

The structuring phase refers to the preparation, development, and final presentation of the cognitive map, which in this case was carried out in two four-hour group sessions. Initial considerations were bound with defining a suitable panel of decision makers, and an appropriate trigger question to guide their discussions and joint development of the collective map.

Underlying these decisions with regard to participants and the guiding thread for their discussions, was the previously defined research problem. Namely, our aim to operationalize IEO in such a way that a framework for its measurement, and for the classification of individuals with regard to this characteristic, could be created through the combined use of cognitive mapping and TODIM.

In terms of participants, caution was taken to ensure that the final panel of decision makers had both a high level of expertise and a diversity of experiences within the field. It has previously been noted that having a panel of experts can greatly improve the quality and "reliability of the final model" (Yaman and Polat 2009, p. 387). In addition, given the different outcomes that can result from entrepreneurial activities, it was of interest to have a panel reflective of these different possibilities; e.g.: starting a new business with visible success; starting a business but being forced to close (through bankruptcy or liquidation); having recent experience with new business creation; or being responsible for entrepreneurial activities (new product or service launches) within an existing company.

The final panel was thus comprised of six individuals with varying degrees and types of experience with entrepreneurship and entrepreneurial activities. While there are no strict guidelines with regard to the ideal panel size, the number of participants in this study was sufficient to guarantee a fruitful diversity of perspectives, but at the same time small enough to allow the researcher to relate to on a personal level (cf. Eden and Ackermann 2001b; Ferreira et al. 2015a). The group sessions were facilitated by an experienced researcher, and a team colleague responsible for registering the results.

\section{The SODA approach and the collective cognitive map}

The structuring phase started with the first group session. Although it is also possible to initiate this stage with individual work sessions - i.e. an approach known as Strategic 
Options Development and Analysis I (SODA I) -, in light of practical issues relating to participants' limited availability, we opted to go straight into the group sessions (i.e. SODA II), using the "post-its technique" (see Ackermann and Eden 2001).

The technique and the goals of the study were explained to participants to ensure a clear and common understanding of the aims and procedures. The discussion was then kicked off with the following trigger question: "Based on your own values and professional experience, what are the characteristics of a great entrepreneur?" This question thus served as the guide for subsequent discussion, the reference point participants were guided back to whenever that discussion strayed, and the starting point for the decision support.

As per the "post-its technique", participants wrote their answers to the trigger question on individual post-its, with care being taken that each post-it should contain only a single characteristic or determinant of a great entrepreneur. This procedure, in addition to participants' individual opinions, was heavily based on the results of intensive group discussion throughout - a reflection of the process-oriented and constructivist nature of the methodology being used. The procedure was furthermore continued until participants felt that "saturation" had been achieved, and expressed satisfaction with the number of determinants obtained and the depth of discussion that accompanied their identification.

The facilitator's role, in both the initial and in the subsequent stages, was crucial, guiding the discussion and ensuring that it stayed focused on the topic at hand. Another of the facilitator's responsibilities was to guarantee that all the participants had a voice in the decision-making process and that this process was as equitable as possible. Ultimately, all the ideas generated were discussed by the group on a collective basis, giving the participants a sense of ownership over the process, and placing the focus on the concepts and ideas, rather than on who (first) put them forth.

In the second stage, the participants then revisited each of the characteristics or criteria identified, and re-arranged the post-its into clusters representing broad areas of concern. Finally, they were asked to focus on each of these areas of concern, and reorganize the criteria within them in terms of the cause-and-effect relationships between them. Each of these stages allowed for additional discussion and learning with regard to the issue at hand, and the process concluded with the group's consensus on the form and content of the resulting collective or congregated map. The construction of this map was supported by the Decision Explorer software (www.banxia.com), and can be seen in Fig. 1.

Figure 1 is illustrative of the comprehensiveness and complexity of the collective cognitive map created, which, despite its richness, allows for an easy visualization of the determinants of IEO and the relationships between them (a full and editable version can be obtained from the authors upon request). In addition, the process of arriving at the map, because it was based on discussion and negotiation, added depth to participants' understanding of the concept. The resulting map is, of course, subjective, insofar as such maps are always contingent on the participants involved, the decision context, the duration of the sessions, and even the facilitator's level of experience. This does not, however, diminish their importance or utility (cf. Eden and Ackermann 2004).

The map depicted in Fig. 1, for instance, represents the consensus of a group of experts on the criteria which should be used to measure IEO. Underlying it is an iterative process of learning and knowledge creation in which the decision makers were 


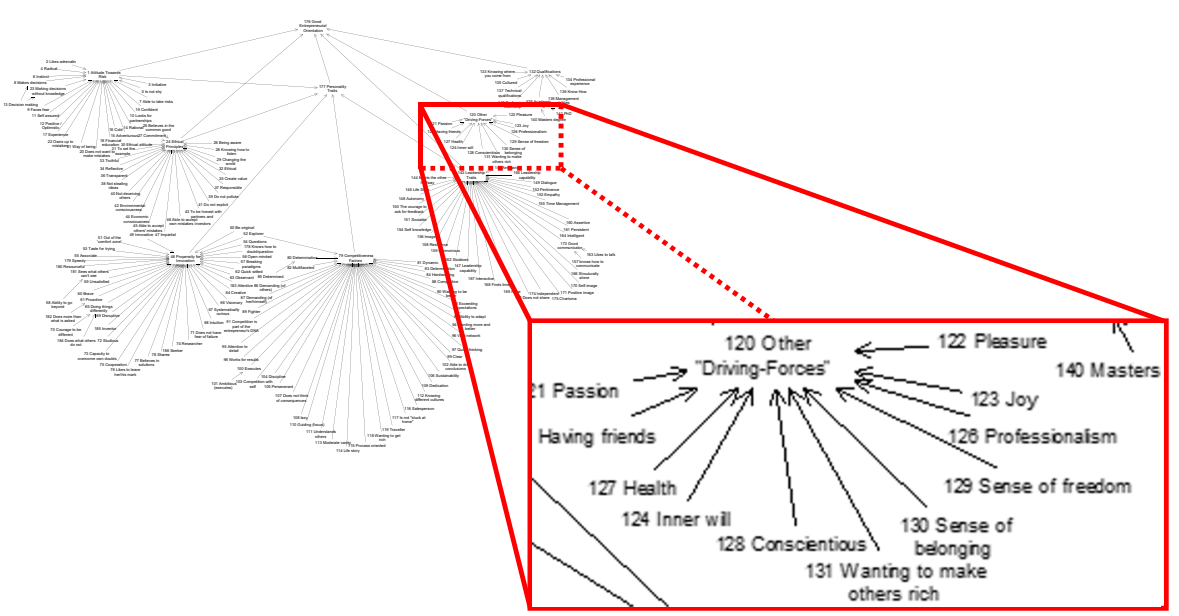

Source: Adapted from Ferreira et al. (2015c).

Fig. 1 Collective cognitive map

directly involved. Furthermore, because it is process-oriented and constructivist in nature, this approach always allows for adjustments.

\section{Tree of criteria and impact levels}

Following Keeney's $(1992,1994)$ methodological guidelines, once the collective map has been arrived at, the next step is to analyze the key evaluation criteria (CTRs) of the decision problem or concept at hand, as previously identified in the collective map.

In the current study, this stage of the process was carried out in a second group session, in which participants focused on the primary concepts previously identified; namely those with a direct link to the central concept of "a high level of IEO" in the collective map. By identifying these concepts or determinants, and subsequently the downstream concepts upon which they depend, with the aid of the facilitator, the group was able to develop the tree of criteria illustrated in Fig. 2.

Figure 2 thus represents the final version of the tree, agreed upon and approved by the group, with the CTRs marked in bold. It is worth noting that, similar to the steps which preceded it, this stage was also based on a deep group discussion, facilitated by a researcher with many years of experience with the methodology.

The tree shows seven CTRs, pertaining to three wider dimensions of IEO (Qualifications, Personality Traits and Complementary Aspects), namely:

- Qualifications and Practical Experience $\left(\mathrm{CTR}_{1}\right)$ - underlines the importance of academic qualifications, professional experience and managerial competence;

- Leadership Traits $\left(\mathrm{CTR}_{2}\right)$ - addresses the fact that an entrepreneur must also be a leader, and is measured through factors such as the individual's charisma, competence, resilience, empathy and assertiveness, among others;

- Propensity to Innovate $\left(\mathrm{CTR}_{3}\right)$ - underpinning this criterion are factors such as vision, creativity, courage, acuity, open-mindedness and intuition. That is an 


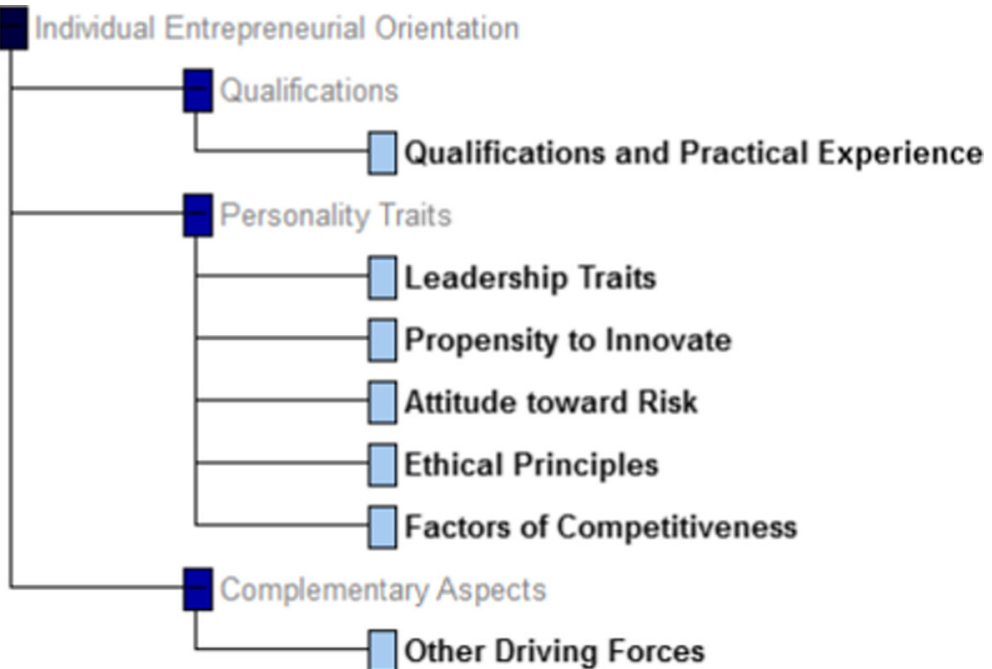

Fig. 2 Tree of criteria for IEO measurement

entrepreneur should be able to create and support new ideas, products and services, without fear of failure;

- Attitude toward Risk $\left(\mathrm{CTR}_{4}\right)$ - consistent with prior research, individuals' attitude toward risk was seen as an important determinant for the measurement of IEO. Participants considered that a high level of IEO requires a correspondingly high level of tolerance toward risk;

- Ethical Principles $\left(\mathrm{CTR}_{5}\right)$ - relates to issues such as honesty (dealing with investors, partners, consumers and other stakeholders in general), transparency, respect for the environment and creating value. Unlike attitude toward risk, which is a commonly used measure of entrepreneurship, individuals' ethical stance tends to be overlooked in such assessments; however, it is a very relevant and increasingly important determinant of entrepreneurial success in the current business environment;

- Factors of Competitiveness $\left(\mathrm{CTR}_{6}\right)$ - relates to the dynamism, discipline and determination (among others), which participants considered were fundamental to assess an IEO. According to the panel, an entrepreneur is attentive to detail and holds both herself and others to high standards of performance;

- Other Driving Forces $\left(\mathrm{CTR}_{7}\right)$ - takes into account factors such as passion, the desire for personal and professional freedom, and the individual's ability to network.

Once the tree of criteria had been agreed upon by the participants, a set of ordered performance (or impact) levels, i.e. a descriptor, was defined for each CTR. Descriptors can be qualitative, quantitative or mixed. As with the previous steps, this was carried out with the direct participation of all the panel members. For instance, for $\mathrm{CTR}_{3}$, a quantitative descriptor comprising five levels was built. These impact levels $\left(L_{i}\right.$ with $i=1,2, \ldots, 5)$ resulted from an adaptation of the Least Preferred Co-Worker Scale (Fiedler 1965, 1967), and the aim was to allow individuals to be assessed in propensity to innovate, based on the underlying determinants of this CTR that the participants 
considered most crucial. In this case, these were the ability to associate concepts, to have an enquiring mind, the willingness to make efforts, observational capabilities, and the ability to network. Although in practice this process was carried out for each one of the seven previously determined CTRs, Table 1 presents, for illustrative purposes, the descriptor for $\mathrm{CTR}_{3}$.

The "INOV index" in Table 1 is an integer number within the impact levels established by the adapted LPC scale and number of sub-criteria involved (in this case, five). Based on the panel's values and opinions, the greater the value of this index, the greater an individual's propensity to innovate and for entrepreneurship. In addition, two levels of the INOV index $\left(\mathrm{L}_{2}\right.$ and $\left.\mathrm{L}_{3}\right)$ were defined as constituting a "good" and a "neutral" level of innovation performance respectively. Identifying these two levels was important because, in doing so, we created "anchors" that facilitated subsequent cognitive comparisons between performance levels (for technical details, see Ferreira et al. 2014, 2015c). Once this procedure had been carried out for all the CTRs, participants moved to the evaluation stage.

\section{The evaluation phase}

A third and final group session, lasting for seven hours, was carried out for the evaluation phase. In this session, the participants worked together to determine the trade-offs among the previously defined impact levels and evaluation criteria. Once this had been achieved, the resulting evaluation framework was applied to test its validity and relevance.

\section{The TODIM method and its foundations}

The TODIM method was developed in the 1990s (cf. Gomes and Lima 1991) and is based on the Prospect Theory (Kahneman and Tversky 1979), a theory so relevant that, in 2002, it partially justified the attribution of the Nobel Prize to Kahneman. Developed within the field of Behavioral Economics, but extensively applied in many other fields, the theory describes the way individuals' choose in situations involving risk, and where the probability of different (risky) outcomes is known. Specifically, it proposes that such choices are made on the basis of individuals' valuations of gains and losses (which they evaluate differently based on certain heuristics), rather than on "final assets"; and replaces probabilities by "decision weights" (Kahneman and Tversky 1979).

The certainty heuristic describes our tendency to "underweight outcomes that are merely probable in comparison with outcomes that are obtained with certainty"; and the "isolation effect [...] leads to inconsistent preferences when the same choice is

Table 1 Descriptor and impact levels for $\mathrm{CTR}_{3}$

\begin{tabular}{ll}
\hline Level & Description \\
\hline $\mathrm{L}_{1}$ & INOV Index $\in[35-40]$ \\
Good & INOV Index $\in[26-34]$ \\
Neutral & INOV Index $\in[20-25]$ \\
$\mathrm{L}_{4}$ & INOV Index $\in[11-19]$ \\
$\mathrm{L}_{5}$ & INOV Index $\in[5-10]$ \\
\hline
\end{tabular}


presented in different forms" (Kahneman and Tversky 1979, p. 263). The resulting value function for decision making under risk is thus S-shaped: "concave for gains, [...] convex for losses, and generally steeper for losses than for gains" (a reflection of loss aversion, as illustrated in Fig. 3).

While the underlying theory of TODIM is the Prospect Theory, in practical terms the method is based on pairwise comparisons. A verbal scale is typically used to carry out these comparisons, endowing the method with great simplicity; but the rating values are then numerical and normalized. Therefore, qualitative evaluations (made on verbal scales) are transformed into cardinal values, with the added benefit that the method's mathematical foundations preclude the possibility of inconsistencies in the ratings and comparisons.

The method also allows for the development of non-linear aggregation functions for the evaluation of different alternatives. These evaluations come from the analysis of each alternative's performance with regard to the previously defined assessment criteria. The result is an evaluation matrix, called "matrix of partial desirabilities" (Rangel et al. 2011, p. 239), as illustrated in Table 2 for the normalized values $A=\left[A_{n m}\right]$.

In the next step, one of the criteria - typically the one with the greatest weight - is taken as the reference $r$, and used to calculate matrices of partial dominance, and subsequently a matrix of overall dominance (cf. Gomes et al. 2009; Moshkovich et al. 2011; Jalali et al. 2015). If we consider $w_{r c}$ as the substitution rate of a certain criterion $c$ in relation to the reference criterion $r$, the measure of dominance of an alternative $A_{i}$ over another alternative $A_{j}$ is given by formulation (1) (cf. Gomes et al. 2009):

$$
\delta\left(A_{i}, A_{j}\right)=\sum_{c=1}^{m} \Phi_{c}\left(A_{i}, A_{j}\right), \forall(i, j)
$$

where:

$$
\Phi_{c}\left(A_{i}, A_{j}\right)=\left\{\begin{array}{l}
\sqrt{\frac{w_{r c}\left(P_{i c}-P_{j c}\right)}{\sum_{c=1}^{m} w_{r c}}} \text { if }\left(P_{i c}-P_{j c}\right)>0 \\
0 \quad \text { if }\left(P_{i c}-P_{j c}\right)=0 \\
\frac{-1}{\theta} \sqrt{\frac{\left(\sum_{c=1}^{m} w_{r c}\right)\left(P_{j c}-P_{i c}\right)}{w_{r c}}} \text { if }\left(P_{i c}-P_{j c}\right)<0
\end{array}\right.
$$

with:

$\delta\left(A_{i}, A_{j}\right)$ represents the measurement of dominance of $A_{i}$ over $A_{j}$;

$m$ is the number of criteria;

$c$ is any criterion, for $c=1, \ldots, m$;

$w_{r c}$ is the substitution rate of the criterion $c$ by the reference criterion $r$;

$P_{i c}$ and $P_{j c}$ are, respectively, the performances of $A_{i}$ and $A_{j}$ in relation to $c$;

$\theta$ is the attenuation factor of losses.

In the formulation above, $\Phi_{c}\left(A_{i}, A_{j}\right)$ represents the contribution of criterion $c$ to the function $\delta\left(A_{i}, A_{j}\right)$, when a pairwise comparison between $A_{i}$ and $A_{j}$ is carried out. If $\left(P_{i c}{ }^{-}\right.$ 


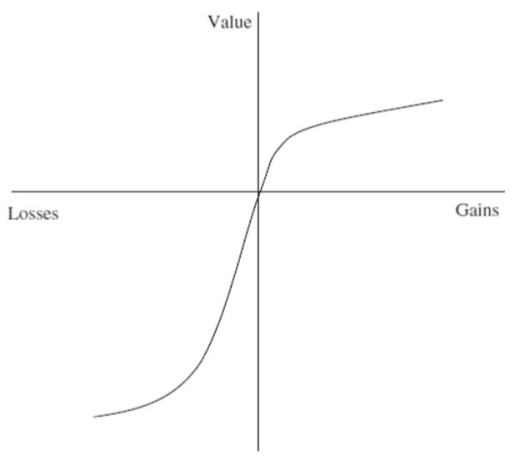

Source: Kahneman and Tversky (1979).

Fig. 3 Value function of the prospect theory

$\left.P_{j c}\right)$ is positive, it represents an increase to the function $\delta\left(A_{i}, A_{j}\right)$, such that $\Phi_{c}\left(A_{i}, A_{j}\right)$ should correspond to formulation (2a). If $\left(P_{i c}-P_{j c}\right)$ is null, there is no contribution to $\delta\left(A_{i}, A_{j}\right)$, and $\Phi_{c}\left(A_{i}, A_{j}\right)$ should correspond to formulation (2b). Finally, if $\left(P_{i c}-P_{j c}\right)$ is negative, $\Phi_{c}\left(A_{i}, A_{j}\right)$ will be represented by formulation (2c).

Once a partial dominance matrix has been derived for each of the criteria, the overall dominance matrix can be calculated by adding the elements of the partial performance matrices. The final matrix is then normalized according to formulation (3) (cf. Gomes et al. 2009), allowing an overall value to be obtained for each alternative - its "measure of desirability or global utility" (Rangel et al. 2011, p. 240-241). The alternatives can then all be ranked according to their overall scores.

$$
\xi_{i}=\frac{\sum_{j=1}^{n} \delta\left(A_{i}, A_{j}\right)-\min \sum_{j=1}^{n} \delta\left(A_{i}, A_{j}\right)}{\max \sum_{j=1}^{n} \delta\left(A_{i}, A_{j}\right)-\min \sum_{j=1}^{n} \delta\left(A_{i}, A_{j}\right)}
$$

As the discussion above shows, despite its simplicity, the TODIM method has a solid mathematical foundation (Gomes and Rangel 2009; Rangel et al. 2009), and furthermore allows for the incorporation of risk in the decision making process $-\mathrm{a}$

Table 2 Matrix of partial desirabilities

\begin{tabular}{lllllll}
\hline Alternatives & \multicolumn{2}{l}{ Criteria } & & & & \\
\cline { 2 - 6 } & $C_{1}$ & $C_{2}$ & $\ldots$ & $C_{j}$ & $\ldots$ & $C_{m}$ \\
\hline$A_{1}$ & $P_{11}$ & $P_{12}$ & $\ldots$ & $P_{1 j}$ & $\ldots$ & $P_{l m}$ \\
$A_{2}$ & $P_{21}$ & $P_{22}$ & $\ldots$ & $P_{2 j}$ & $\ldots$ & $P_{2 m}$ \\
$\ldots$ & $\ldots$ & $\ldots$ & $\ldots$ & $\ldots$ & $\ldots$ & $\ldots$ \\
$A_{i}$ & $P_{i 1}$ & $P_{i 2}$ & $\ldots$ & $P_{i j}$ & $\ldots$ & $P_{i m}$ \\
$\ldots$ & $\ldots$ & $\ldots$ & $\ldots$ & $\ldots$ & $\ldots$ & $\ldots$ \\
$A_{n}$ & $P_{n 1}$ & $P_{n 2}$ & $\ldots$ & $P_{n j}$ & $\ldots$ & $P_{n m}$ \\
\hline
\end{tabular}

Source: Gomes and Rangel (2009) 
particularly relevant feature in what pertains to the study of entrepreneurship. Although inherently subjective, given that it is based on semantic judgments, this is also a feature of decision problems in general (cf. Eden and Ackermann 2001a; Santos et al. 2002; Eden 2004). Indeed, one of the major contributions of MCDA techniques is precisely to make such subjectivity explicit.

\section{IEO Evaluation and framework testing}

As per the methodological description above, in the current study the evaluation stage started with a matrix of parity comparisons, which participants filled in so that the CTRs could be ordered. When a criterion was deemed globally preferable to another, it was given a value of " 1 "; and it was attributed a value of " 0 " otherwise. The sum of these values determined the final ranking of the CTRs, as validated by the panel members. Next, a series of pairwise comparisons using Saaty's (1980) fundamental scale took place and the weights obtained can be seen in Table 3.

The model was then tested using information on 17 individuals (henceforth Deltas) participating in an executive education business course and known to all the participants. The aim was to rank these Deltas according to their level of IEO, by evaluating each one based on the previously defined CTRs and weights. The result of this process can be seen in Table 4.

Although this sample is not very large by conventional standards, such a sample size is not uncommon for framework testing in MCDA studies (cf. Belton and Stewart 2002; Gomes and Rangel 2009; Ferreira et al. 2011). This is a reflection of the constructivist nature of the MCDA approach, which is quite distinct from traditional methods using existing data. Furthermore, the aim here was simply an initial test of the developed framework, created according to the decision makers' value systems and professional experience. The framework is then flexible enough to allow the addition of new data points, and indeed increases in accuracy as this is done.

The evaluations presented in Table 4 were then standardized, by dividing the value obtained for each Delta by the sum of the values obtained in each CTR, resulting in the matrix of partial desirabilities represented in Table 5.

In order to obtain the Deltas' overall scores, the Sapiens TODIM software (www. comp.ime.eb.br) was used. This software applies the mathematical formulation previously presented and, given the values of the matrix of partial desirabilities, is

Table 3 Criteria weights

\begin{tabular}{lllllllll}
\hline & CRT07 & CRT06 & CRT02 & CRT03 & CRT04 & CRT05 & CRT01 & Normalized Weight \\
\hline CRT07 & - & 3.0 & 3.0 & 3.0 & 5.0 & 5.0 & 8.0 & 0.345742 \\
CRT06 & - & - & 2.0 & 2.0 & 3.0 & 5.0 & 7.0 & 0.201192 \\
CRT02 & - & - & - & 2.0 & 3.0 & 5.0 & 7.0 & 0.166544 \\
CRT03 & - & - & - & - & 3.0 & 5.0 & 7.0 & 0.137863 \\
CRT04 & - & - & - & - & - & 3.0 & 7.0 & 0.078625 \\
CRT05 & - & - & - & - & - & - & 7.0 & 0.050089 \\
CRT01 & - & - & - & - & - & - & - & 0.019945 \\
\hline
\end{tabular}


Table 4 Partial performance of the deltas [levels and scores]

\begin{tabular}{|c|c|c|c|c|c|c|c|c|c|c|c|c|c|c|}
\hline \multirow{3}{*}{$\begin{array}{l}\text { Alternatives } \\
\text { Delta } 01\end{array}$} & \multicolumn{14}{|c|}{ Criteria } \\
\hline & \multicolumn{2}{|c|}{ CRT07 } & \multicolumn{2}{|c|}{ CRT06 } & \multicolumn{2}{|c|}{ CRT02 } & \multicolumn{2}{|c|}{ CRT03 } & \multicolumn{2}{|c|}{ CRT04 } & \multicolumn{2}{|c|}{ CRT05 } & \multicolumn{2}{|c|}{ CRT01 } \\
\hline & $\mathrm{L}_{2}$ & 6.5 & $\mathrm{~L}_{3}$ & 4.5 & $\mathrm{~L}_{4}$ & 3.5 & $\mathrm{~L}_{3}$ & 4.5 & $\mathrm{~L}_{1}$ & 9.0 & $\mathrm{~L}_{3}$ & 4.5 & $\mathrm{~L}_{5}$ & 5.0 \\
\hline Delta 02 & $\mathrm{~L}_{1}$ & 8.5 & $\mathrm{~L}_{3}$ & 4.5 & $\mathrm{~L}_{3}$ & 6.5 & $\mathrm{~L}_{2}$ & 6.5 & $\mathrm{~L}_{5}$ & 5.0 & $\mathrm{~L}_{3}$ & 4.5 & $\mathrm{~L}_{4}$ & 6.0 \\
\hline Delta 03 & $\mathrm{~L}_{4}$ & 2.5 & $\mathrm{~L}_{3}$ & 4.5 & $\mathrm{~L}_{5}$ & 2.0 & $\mathrm{~L}_{4}$ & 2.5 & $\mathrm{~L}_{7}$ & 3.0 & $\mathrm{~L}_{3}$ & 4.5 & $\mathrm{~L}_{8}$ & 2.0 \\
\hline Delta 04 & $\mathrm{~L}_{1}$ & 8.5 & $\mathrm{~L}_{2}$ & 6.5 & $\mathrm{~L}_{1}$ & 9.0 & $\mathrm{~L}_{2}$ & 6.5 & $\mathrm{~L}_{1}$ & 9.0 & $\mathrm{~L}_{3}$ & 4.5 & $\mathrm{~L}_{4}$ & 6.0 \\
\hline Delta 05 & $\mathrm{~L}_{2}$ & 6.5 & $\mathrm{~L}_{3}$ & 4.5 & $\mathrm{~L}_{4}$ & 3.5 & $\mathrm{~L}_{3}$ & 4.5 & $\mathrm{~L}_{4}$ & 6.0 & $\mathrm{~L}_{4}$ & 2.5 & $\mathrm{~L}_{8}$ & 2.0 \\
\hline Delta 06 & $\mathrm{~L}_{4}$ & 2.5 & $\mathrm{~L}_{4}$ & 2.5 & $\mathrm{~L}_{4}$ & 3.5 & $\mathrm{~L}_{4}$ & 2.5 & $\mathrm{~L}_{1}$ & 9.0 & $\mathrm{~L}_{4}$ & 2.5 & $\mathrm{~L}_{8}$ & 2.0 \\
\hline Delta 07 & $\mathrm{~L}_{2}$ & 6.5 & $\mathrm{~L}_{2}$ & 6.5 & $\mathrm{~L}_{3}$ & 6.5 & $\mathrm{~L}_{2}$ & 6.5 & $\mathrm{~L}_{3}$ & 7.0 & $\mathrm{~L}_{3}$ & 4.5 & $\mathrm{~L}_{6}$ & 4.0 \\
\hline Delta 08 & $\mathrm{~L}_{2}$ & 6.5 & $\mathrm{~L}_{2}$ & 6.5 & $\mathrm{~L}_{3}$ & 6.5 & $\mathrm{~L}_{2}$ & 6.5 & $\mathrm{~L}_{1}$ & 9.0 & $\mathrm{~L}_{3}$ & 4.5 & $\mathrm{~L}_{7}$ & 3.0 \\
\hline Delta 09 & $\mathrm{~L}_{2}$ & 6.5 & $\mathrm{~L}_{3}$ & 4.5 & $\mathrm{~L}_{4}$ & 3.5 & $\mathrm{~L}_{4}$ & 2.5 & $\mathrm{~L}_{7}$ & 3.0 & $\mathrm{~L}_{3}$ & 4.5 & $\mathrm{~L}_{6}$ & 4.0 \\
\hline Delta 10 & $\mathrm{~L}_{3}$ & 4.5 & $\mathrm{~L}_{2}$ & 6.5 & $\mathrm{~L}_{4}$ & 3.5 & $\mathrm{~L}_{3}$ & 4.5 & $\mathrm{~L}_{1}$ & 9.0 & $\mathrm{~L}_{4}$ & 2.5 & $\mathrm{~L}_{6}$ & 4.0 \\
\hline Delta 11 & $\mathrm{~L}_{3}$ & 4.5 & $\mathrm{~L}_{2}$ & 6.5 & $\mathrm{~L}_{3}$ & 6.5 & $\mathrm{~L}_{3}$ & 4.5 & $\mathrm{~L}_{5}$ & 5.0 & $\mathrm{~L}_{4}$ & 2.5 & $\mathrm{~L}_{8}$ & 2.0 \\
\hline Delta 12 & $\mathrm{~L}_{2}$ & 6.5 & $\mathrm{~L}_{2}$ & 6.5 & $\mathrm{~L}_{3}$ & 6.5 & $\mathrm{~L}_{2}$ & 6.5 & $\mathrm{~L}_{3}$ & 7.0 & $\mathrm{~L}_{3}$ & 4.5 & $\mathrm{~L}_{6}$ & 4.0 \\
\hline Delta 13 & $\mathrm{~L}_{2}$ & 6.5 & $\mathrm{~L}_{2}$ & 6.5 & $\mathrm{~L}_{3}$ & 6.5 & $\mathrm{~L}_{2}$ & 6.5 & $\mathrm{~L}_{7}$ & 3.0 & $\mathrm{~L}_{2}$ & 6.5 & $\mathrm{~L}_{8}$ & 2.0 \\
\hline Delta 14 & $\mathrm{~L}_{2}$ & 6.5 & $\mathrm{~L}_{2}$ & 6.5 & $\mathrm{~L}_{1}$ & 9.0 & $\mathrm{~L}_{2}$ & 6.5 & $\mathrm{~L}_{4}$ & 6.0 & $\mathrm{~L}_{2}$ & 6.5 & $\mathrm{~L}_{3}$ & 7.0 \\
\hline Delta 15 & $\mathrm{~L}_{2}$ & 6.5 & $\mathrm{~L}_{3}$ & 4.5 & $\mathrm{~L}_{3}$ & 6.5 & $\mathrm{~L}_{3}$ & 4.5 & $\mathrm{~L}_{1}$ & 9.0 & $\mathrm{~L}_{3}$ & 4.5 & $\mathrm{~L}_{8}$ & 2.0 \\
\hline Delta 16 & $\mathrm{~L}_{2}$ & 6.5 & $\mathrm{~L}_{2}$ & 6.5 & $\mathrm{~L}_{3}$ & 6.5 & $\mathrm{~L}_{3}$ & 4.5 & $\mathrm{~L}_{6}$ & 4.0 & $\mathrm{~L}_{2}$ & 6.5 & $\mathrm{~L}_{7}$ & 3.0 \\
\hline Delta 17 & $\mathrm{~L}_{1}$ & 8.5 & $\mathrm{~L}_{2}$ & 6.5 & $\mathrm{~L}_{2}$ & 8.0 & $\mathrm{~L}_{3}$ & 4.5 & $\mathrm{~L}_{2}$ & 8.0 & $\mathrm{~L}_{2}$ & 6.5 & $\mathrm{~L}_{5}$ & 5.0 \\
\hline
\end{tabular}

able to quickly provide Deltas' overall scores, as well as their final positioning, which can be seen in Table 6.

Although the minimum performance in Table 6 is represented by zero, this does not necessarily mean that Delta 03 has a utility equal to zero. Rather, it means that the lowest performance was considered the "zero" of the scale. In order to better understand the Deltas' positioning, two fictitious entrepreneurship thresholds were considered - good and neutral (for technical details, see Ferreira et al. 2014). These allowed zones representing different levels of IEO to be determined, as illustrated in Fig. 4 below. The green vertical line (on the right side of the graph) represents the "good level" - i.e. it corresponds to a (fictitious) Delta assessed as "good" in all the criteria; and the blue vertical line (on the left side of the graph) represents the "neutral" level - a Delta who performs at the neutral level in all the criteria of IEO. Those between the two lines are considered to have "normal" levels of IEO; those on the left of the blue line have "low" levels of IEO; and those on the right of the green line are considered to have high or excellent levels of IEO.

As Fig. 4 shows, five of the Deltas had "normal" levels of IEO, five had a "low" predisposition for IEO, and the remaining seven were considered to have "high" levels of IEO. These overall results were not entirely surprising, when we consider that these Deltas were all engaged in an executive education business course. Figure 4 thus brings together the first two phases of the framework development. In the structuring phase, the determinants of IEO were identified and mapped out according to areas of concern 
Table 5 Matrix of partial desirabilities for the 17 deltas

\begin{tabular}{|c|c|c|c|c|c|c|c|}
\hline \multirow[t]{2}{*}{ Alternatives } & \multicolumn{7}{|l|}{ Criteria } \\
\hline & CRT07 & CRT06 & CRT02 & CRT03 & CRT04 & CRT05 & CRT01 \\
\hline Delta 01 & 0.062201 & 0.047619 & 0.035897 & 0.053254 & 0.081081 & 0.058824 & 0.079365 \\
\hline Delta 02 & 0.081340 & 0.047619 & 0.066667 & 0.076923 & 0.045045 & 0.058824 & 0.095238 \\
\hline Delta 03 & 0.023923 & 0.047619 & 0.020513 & 0.029586 & 0.027027 & 0.058824 & 0.031746 \\
\hline Delta 04 & 0.081340 & 0.068783 & 0.092308 & 0.076923 & 0.081081 & 0.058824 & 0.095238 \\
\hline Delta 05 & 0.062201 & 0.047619 & 0.035897 & 0.053254 & 0.054054 & 0.032680 & 0.031746 \\
\hline Delta 06 & 0.023923 & 0.026455 & 0.035897 & 0.029586 & 0.081081 & 0.032680 & 0.031746 \\
\hline Delta 07 & 0.062201 & 0.068783 & 0.066667 & 0.076923 & 0.063063 & 0.058824 & 0.063492 \\
\hline Delta 08 & 0.062201 & 0.068783 & 0.066667 & 0.076923 & 0.081081 & 0.058824 & 0.047619 \\
\hline Delta 09 & 0.062201 & 0.047619 & 0.035897 & 0.029586 & 0.027027 & 0.058824 & 0.063492 \\
\hline Delta 10 & 0.043062 & 0.068783 & 0.035897 & 0.053254 & 0.081081 & 0.032680 & 0.063492 \\
\hline Delta 11 & 0.043062 & 0.068783 & 0.066667 & 0.053254 & 0.045045 & 0.032680 & 0.031746 \\
\hline Delta 12 & 0.062201 & 0.068783 & 0.066667 & 0.076923 & 0.063063 & 0.058824 & 0.063492 \\
\hline Delta 13 & 0.062201 & 0.068783 & 0.066667 & 0.076923 & 0.027027 & 0.084967 & 0.031746 \\
\hline Delta 14 & 0.062201 & 0.068783 & 0.092308 & 0.076923 & 0.054054 & 0.084967 & 0.111111 \\
\hline Delta 15 & 0.062201 & 0.047619 & 0.066667 & 0.053254 & 0.081081 & 0.058824 & 0.031746 \\
\hline Delta 16 & 0.062201 & 0.068783 & 0.066667 & 0.053254 & 0.036036 & 0.084967 & 0.047619 \\
\hline Delta 17 & 0.081340 & 0.068783 & 0.082051 & 0.053254 & 0.072072 & 0.084967 & 0.079365 \\
\hline
\end{tabular}

Table 6 Overall scores and final ranking

\begin{tabular}{llc}
\hline ALTERNATIVES & OVERALL SCORE & RANKING \\
\hline Delta 04 & 1.000000000000 & 1 \\
Delta 14 & 0.952207637689 & 2 \\
Delta 17 & 0.894388567266 & 3 \\
Delta 07 & 0.775106501415 & 4 \\
Delta 12 & 0.775106501415 & 4 \\
Delta 02 & 0.765062119691 & 6 \\
Delta 08 & 0.737419217169 & 7 \\
Delta 01 & 0.656462732763 & 8 \\
Delta 16 & 0.576369781910 & 9 \\
Delta 13 & 0.528389350049 & 10 \\
Delta 15 & 0.500032760853 & 11 \\
Delta 10 & 0.496571142856 & 12 \\
Delta 09 & 0.341548956489 & 13 \\
Delta 11 & 0.277816332712 & 14 \\
Delta 05 & 0.207121706585 & 15 \\
Delta 06 & 0.025840116517 & 16 \\
Delta 03 & 0.000000000000 & 17 \\
\hline & & 7 \\
\hline
\end{tabular}


and the relationships between criteria within them. In the evaluation phase, these key criteria were ranked and weighted to allow individuals to be assessed in terms of their IEO. Figure 4 illustrates the result of such evaluation. Crucially, it is important to bear in mind that this framework is constructivist and always open to adjustments. Thus, over time, as more Deltas are added to the analysis, it will become more accurate (able to discern between individuals' performance), leading to better recommendations.

\section{The recommendations phase of the study}

Having completed the exercise above and mapped out the Deltas' positioning vis a vis the good and neutral reference lines, the participants expressed their satisfaction not only with the final ranking, but with the process of developing the framework itself. Given its constructivist nature, this process allowed them to continuously improve on the framework and simultaneously deepen their understanding of IEO through continuous discussion.

The practical application of the framework to the 17 Deltas proved to be particularly gratifying, because it allowed the participants to test the framework. The results of this application not only reinforced their belief in the relevance and usefulness of the methodologies used for the evaluation of IEO, but also allowed focused improvement suggestions to be presented, based on the Deltas' partial performance levels.

These results provide empirical evidence of the applicability of the proposed methodologies - namely the combined use of cognitive mapping and the TODIM method - for the evaluation of IEO. The creation of a values-based framework for the assessment of IEO is important not only due to the relative shortage of such models, but because of their practical use for decisions pertaining to business partnerships, resource allocation, and task assignments, among others.

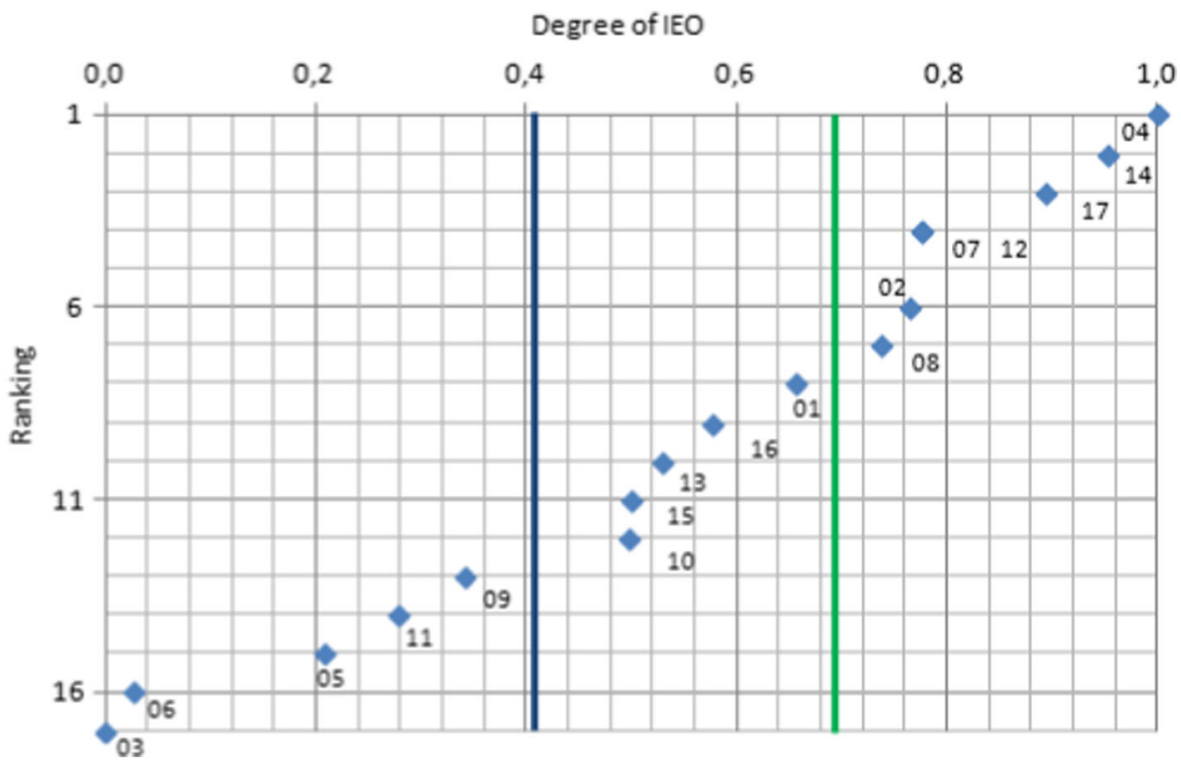

Fig. 4 Deltas' positioning and IEO thresholds [good and neutral] 
The framework created is, of course, context dependent. The aim was never to achieve an "optimal" solution, but rather to adopt a non-prescriptive, process-oriented and constructivist posture. The procedures followed allowed for learning, and a better understanding of IEO and its determinants; however, any extrapolations made therefrom should be carried out with caution and bearing in mind the framework's inherent subjectivity.

\section{Conclusion}

The benefits of entrepreneurial activity in terms of promoting innovation, meeting consumer needs, job creation and stimulating economic growth have long been professed, but have arguably never been as relevant as in the current economic and competitive context. As such, understanding entrepreneurship and individuals' predisposition for entrepreneurial activity is of fundamental importance from both an academic perspective (because of the calls for novel measures of these constructs) and from a practitioner perspective (because of the practical benefits of being able to assess IEO and its determinants). Understanding the factors underlying IEO can help the development of more effective strategies for its enhancement; and frameworks for its assessment can be of fundamental importance to decisions relating to business partnerships, the provision of funding, hiring, and many others.

Within this context, the aim of this paper was to develop a new framework for understanding and evaluating IEO, which might provide greater levels of transparency and a more comprehensive perception of the construct. To this end, we combined cognitive mapping with the TODIM method to create a new tool for the measurement of IEO. Using a panel of decision experts and starting from a constructivist standpoint, a collective map for understanding the determinants of IEO and the relationships between them was created. This map resulted in the identification of over 200 determinants, which were then grouped and ordered. The TODIM method was then applied to create the evaluation framework, and its successful application showed the usefulness of the framework and its ability to measure IEO. More importantly still, it showed the potential of the methodologies used for understanding IEO, and creating valuesbased evaluation frameworks, grounded on and able to promote learning and knowledge sharing. The methodology applied thus not only allowed the identification of hitherto underexplored determinants in the field of IEO (such as ethical considerations, for instance), but weighted these determinants taking risk into account. Furthermore, the constructivist nature of the resulting framework means that it is always amenable to adjustments. While any extrapolations from the current study must be undertaken with caution, given the subjective nature of the methodologies used, it is worth noting that such subjectivity is inherent in all decision making situations. Indeed, MCDA methods aim precisely to make this subjectivity explicit.

The current study thus not only contributed to advance the IEO literature, but is of practical consequence for managers and investors alike. Business success increasingly demands entrepreneurial activities in their diverse forms. Therefore, it is fundamental for managers to not only possess and be able to develop their IEO, but to have the tools to identify entrepreneurial capabilities in others. The methods proposed in the current 
study allow them to create such tools, in a manner consistent with their values and experience.

In terms of future studies, replications of the current study with different panel members or in different contexts would be of great interest. Cross-cultural comparisons would also be of interest, in particular given the country disparities noted in the literature with regard to attitudes to risk for instance, or macro-economic policies for the encouragement of entrepreneurship.

Acknowledgments This study is an outcome of a larger research project on individual entrepreneurial orientation measurement carried out at ISCTE Business School and INDEG-ISCTE, both from the University Institute of Lisbon, Portugal. The authors acknowledge the outstanding collaboration of the panel members: Daniel Yan, Francisco Rebelo, Geni Barbosa, Gonçalo de Paula, Maria Gomes and Pedro Silva.

\section{References}

Ackermann, F. \& Eden, C. (2001). SODA - journey making and mapping in practice. In J. Rosenhead \& J. Mingers (Eds.), Rational analysis for a problematic world revisited: Problem structuring methods for complexity, uncertainty and conflict (pp. 43-60). Chichester: John Wiley \& Sons.

Ackermann, F., Andersen, D., Eden, C., \& Richardson, G. (2011). ScriptsMap: A tool for designing multimethod policy-making workshops. Omega: The International Journal of Management Science, 39(4), 427-434.

Amado, C., Santos, S., \& Marques, P. (2012). Integrating the data envelopment analysis and the balanced scorecard approaches for enhanced performance assessment. Omega: The International Journal of Management Sciences, 40(3), 390-403.

Ananda, J. \& Herath, G. (2009). A critical review of multi-criteria decision making methods with special reference to forest management and planning. Ecological Economics, 68(10), 2535-2548.

Belton, V. \& Stewart, T. (2002). Multiple criteria decision analysis: An integrated approach. Kluwer: Academic Publishers.

Bolton, D. \& Lane, M. (2012). Individual entrepreneurial orientation: development of a measurement instrument. Journal of Education and Training, 54(2), 219-233.

Covin, J. \& Wales, W. (2012). The measurement of entrepreneurial orientation. Entrepreneurship Theory and Practice, 36(4), 677-702.

Eden, C. (2004). Analyzing cognitive maps to help structure issues or problems. European Journal of Operational Research, 159(3), 673-686.

Eden, C. \& Ackermann, F. (2001a). Group decision and negotiation in strategy making. Group Decision and Negotiation, 10(2), 119-140.

Eden, C. \& Ackermann, F. (2001b). SODA - the principles. In J. Rosenhead \& J. Mingers (Eds.), Rational analysis for a problematic world revisited: Problem structuring methods for complexity, uncertainty and conflict (pp. 21-41). Chichester: John Wiley \& Sons.

Eden, C. \& Ackermann, F. (2004). Cognitive mapping expert views for policy analysis in the public sector. European Journal of Operational Research, 152(3), 615-630.

Ferreira, F., Santos, S., \& Rodrigues, P. (2011). Adding value to bank branch performance evaluation using cognitive maps and MCDA: a case study. Journal of the Operational Research Society, 62(7), 13201333.

Ferreira, F., Spahr, R., Santos, S., \& Rodrigues, P. (2012). A multiple criteria framework to evaluate bank branch potential attractiveness. International Journal of Strategic Property Management, 16(3), 254-276.

Ferreira, F., Santos, S., Rodrigues, P., \& Spahr, R. (2014). Evaluating retail banking service quality and convenience with MCDA techniques: a case study at the bank branch level. Journal of Business Economics And Management, 15(1), 1-21.

Ferreira, F., Jalali, M., Ferreira, J., Stankevičienè, J., \& Marques, C. (2015a). Understanding the dynamics behind bank branch service quality in Portugal: pursuing a holistic view using fuzzy cognitive mapping. Service Business. doi:10.1007/s11628-015-0278-x. 
Ferreira, F., Jalali, M., Meidute-Kavaliauskienè, I., \& Viana, B. (2015b). A metacognitive decision making based-approach to bank customer loyalty measurement and management. Technological and Economic Development of Economy, 21(2), 280-300.

Ferreira, F., Marques, C., Bento, P., Ferreira, J., \& Jalali, M. (2015c). Operationalizing and measuring individual entrepreneurial orientation using cognitive mapping and MCDA techniques. Journal of Business Research, 68(12), 2691-2702.

Fiedler, F. (1965). Engineer the job to fit the manager. Harvard Business Review, 43(5), 115-122.

Fiedler, F. (1967). A theory of leadership effectiveness. New York: McGraw-Hill.

Filipe, M., Ferreira, F., \& Santos, S. (2015). A multiple criteria information system for pedagogical evaluation and development of teachers. Journal of the Operational Research Society, 66(11), 1769-1782.

Gavrilova, T., Carlucci, D., \& Schiuma, G. (2013). Art of visual thinking for smart business education. In Proceedings of the 8th International Forum on knowledge asset dynamics (pp. 1754-1761). Croatia: Zagreb.

Goktan, A. \& Gupta, V. (2015). Sex, gender, and individual entrepreneurial orientation: evidence from four countries. International Entrepreneurship And Management Journal, 11(1), 95-112.

Gomes, L. \& Lima, M. (1991). TODIM: basics and application to multicriteria ranking of projects with environmental impacts. Foundations of Computing and Decision Science, 16(4), 113-127.

Gomes, F. \& Rangel, L. (2009). An application of the TODIM method to the multicriteria rental evaluation of residential properties. European Journal of Operational Research, 193(1), 204-211.

Gomes, L., Rangel, L., \& Maranhão, F. (2009). Multicriteria analysis of natural gas destination in Brazil: an application of the TODIM method. Mathematical And Computer Modelling, 50(1/2), 92-100.

Howick, S. \& Ackermann, F. (2011). Mixing OR methods in practice: past, present and future directions. European Journal of Operational Research, 215(3), 503-511.

Jalali, M., Ferreira, F., Ferreira, J., \& Meidutė-Kavaliauskienè, I. (2015). Integrating metacognitive and psychometric decision making approaches for bank customer loyalty measurement. International Journal of Information Technology and Decision Making. doi:10.1142/S0219622015500236.

Kahneman, D. \& Tversky, A. (1979). Prospect theory: an analysis of decision under risk. Econometrica, 47(2), 263-292.

Keeney, R. (1992). Value-focused thinking: A path to creative decisionmaking. Harvard: University Press Harvard.

Keeney, R. (1994). Creativity in decision making with value-focused thinking. MIT Sloan Management Review, 35(4), 33-41.

Li, Y., Huang, J., \& Tsai, M. (2009). Entrepreneurial orientation and firm performance: the role of knowledge creation process. Industrial Marketing Management, 38(4), 440-449.

Liu, P., Jin, F., Zhang, X., Su, Y., \& Wang, M. (2011). Research on the multi-attribute decision-making under risk with interval probability based on prospect theory and the uncertain linguistic variables. KnowledgeBased Systems, 24(4), 554-561.

Lumpkin, G. \& Dess, G. (1996). Clarifying the entrepreneurial orientation construct and linking it to performance. Academy Of Management Review, 21(1), 135-172.

Lumpkin, G. \& Dess, G. (2001). Linking two dimensions of entrepreneurial orientation to firm performance: the moderating role of environment and industry life cycle. Journal of Business Venturing, 16(5), 429451.

Lyon, D., Lumpkin, G., \& Dess, G. (2000). Enhancing entrepreneurial orientation research: operationalizing and measuring a key strategic decision making process. Journal of Management, 26(5), 1055-1085.

Marques, C., Ferreira, J., Ferreira, F., \& Lages, M. (2013). Entrepreneurial orientation and motivation to start up a business: evidence from the health service industry. International Entrepreneurship And Management Journal, 9(1), 77-94.

Miller, D. (1983). The correlates of entrepreneurship in three types of firms. Management Science, 29(7), 770791.

Miller, D. (2011). Miller (1983) revisited: a reflection on EO research and some suggestions for the future. Entrepreneurship Theory and Practice, 35(5), 873-894.

Mitchell, R., Busenitz, L., Lant, T., McDougall, P., Morse, E., \& Smith, J. (2002). Toward a theory of entrepreneurial cognition: rethinking the people side of entrepreneurship research. Entrepreneurship Theory and Practice, 27(2), 93-104.

Moshkovich, H., Gomes, L., \& Mechitov, A. (2011). An integrated multicriteria decision-making approach to real estate evaluation: case of the TODIM method. Pesquisa Operacional, 31(1), 3-20.

Rangel, L., Gomes, L., \& Moreira, R. (2009). Decision theory with multiple criteria: an application of ELECTRE IV and TODIM to sebrae/RJ. Pesquisa Operacional, 29(3), 577-590. 
Rangel, L., Gomes, L., \& Cardoso, F. (2011). An application of the TODIM method to the evaluation of broadband internet plans. Pesquisa Operacional, 31(2), 235-249.

Rauch, A., Wiklund, J., Lumpkin, G., \& Frese, M. (2009). Entrepreneurial orientation and business performance: an assessment of past research and suggestions for the future. Entrepreneurship Theory and Practice, 33(3), 761-787.

Saaty, T. (1980). The analytic hierarchy process: Planning, priority setting, resource allocation. New York: McGraw-Hill.

Santos, S., Belton, V., \& Howick, S. (2002). Adding value to performance measurement by using systems dynamics and multicriteria analysis. International Journal of Operations \& Production Management, 22(11), 1246-1272.

Santos, S., Belton, V., \& Howick, S. (2008). Enhanced performance measuring using or: a case study. Journal of the Operational Research Society, 59(6), 762-775.

Shook, C., Priem, R., \& McGee, J. (2003). Venture creation and the enterprising individual: a review and synthesis. Journal of Management, 29(3), 379-399.

Smith, P. \& Goddard, M. (2002). Performance management and operational research: a marriage made in heaven? Journal of the Operational Research Society, 53(3), 247-255.

Spedale, S. \& Watson, T. (2014). The emergence of entrepreneurial action: at the crossroads between institutional logics and individual life-orientation. International Small Business Journal, 32(7), 759-776.

Steenkamp, J. \& Wittink, D. (1994). The metric quality of full-profile judgments and the number-of-attributelevels effect in conjoint analysis. International Journal of Research in Marketing, 11, 275-286.

Thompson, E. (2009). Individual entrepreneurial intent: construct clarification and development of an internationally reliable metric. Entrepreneurship Theory and Practice, 33(3), 669-694.

van Til, J., Dolan, J., Stiggelbout, A., Groothuis, K., \& Ijzerman, M. (2008). The use of multi-criteria decision analysis weight elicitation techniques in patients with mild cognitive impairment. Patient, 1(2), 127-135.

Wang, C. (2008). Entrepreneurial orientation, learning orientation, and firm performance. Entrepreneurship Theory and Practice, 32(4), 635-657.

Wittink, D., Krishnamurthi, L., \& Nutter, J. (1982). Comparing derived importance weights across attributes. Journal of Consumer Research, 8, 471-474.

Wittink, D., Krishnamurthi, L., \& Rebstein, D. (1989). The effect of differences in the number of attribute levels on conjoint results. Marketing Letters, 1, 113-123.

Yaman, D. \& Polat, S. (2009). A fuzzy cognitive map approach for effect-based operations: an illustrative case. Information Sciences, 179(4), 382-403. 